\title{
Chemoselective Hydrosilylation of Olefin/Ketone Catalyzed by Iminobipyridine Fe and Co complexes
}

Katsuaki Kobayashi, Daisuke Taguchi, Toshiyuki Moriuchi, Hiroshi Nakazawa

\begin{tabular}{|c|c|}
\hline Citation & ChemCatChem. 12(3); 736-739 \\
\hline Issue Date & $2020-02-06$ \\
\hline Type & Journal Article \\
\hline Textversion & Author \\
\hline Rights & $\begin{array}{l}\text { This is the peer reviewed version of the following article: ChemCatChem. Vol.12, } \\
\text { Issu.3, Page.736-739, which has been published in final form at } \\
\text { https://doi.org/10.1002/cctc. } 201901717 \text {. This article may be used for non-commercial } \\
\text { purposes in accordance with Wiley Terms and Conditions for Use of Self-Archived } \\
\text { Versions. This article may not be enhanced, enriched or otherwise transformed into } \\
\text { a derivative work, without express permission from Wiley or by statutory rights } \\
\text { under applicable legislation. Copyright notices must not be removed, obscured or } \\
\text { modified. The article must be linked to Wiley's version of record on Wiley Online } \\
\text { Library and any embedding, framing or otherwise making available the article or } \\
\text { pages thereof by third parties from platforms, services and websites other than } \\
\text { Wiley Online Library must be prohibited. }\end{array}$ \\
\hline DOI & $10.1002 /$ cctc. 201901717 \\
\hline
\end{tabular}

\author{
Self-Archiving by Author(s) \\ Placed on: Osaka City University
}




\section{Chemoselectivity conversion of olefin/ketone hydrosilylation reaction catalyzed by Fe and Co complexes bearing an iminobipyridine ligand}

\begin{abstract}
Katsuaki Kobayashi, ${ }^{*}$ Daisuke Taguchi, Toshiyuki Mor
Abstract: The chemoselective hydrosilylation of olefins and ketones catalyzed by $\mathrm{Fe}$ and $\mathrm{Co}$ complexes bearing an iminobipyridine derivative ligand was investigated. The reaction of a 1:1 mixture of styrene and acetophenone over the Fe catalyst achieved selective hydrosilylation of acetophenone. In contrast, the corresponding Co complex showed the opposite selectivity-styrene-selective hydrosilylation. The reaction of 3-acetylstyrene with both olefin and ketone moieties in the molecule showed that the Co complex catalyzed olefin-selective hydrosilylation. In contrast, the addition of pyridine to the Co-catalyzed system showed the opposite chemoselectivity, affording the ketone hydrosilylated product. The chemoselectivity of olefin/ketone hydrosilylation was switched by replacing the central metal of the complex with the iminobipyridine derivative ligand and by changing the simple reaction conditions (absence or presence of pyridine) using an identical Co complex.
\end{abstract}

Hydrosilylation is widely used to obtain organosilane compounds, and many catalysts for hydrosilylation have been developed to date. Recent studies in this field involve the development of catalysts that facilitate hydrosilylation at olefin or carbonyl moieties while excluding other functional groups, such as halides and hydroxy groups from the reaction. These chemoselective hydrosilylation reactions have been reported for olefin bearing halogeno, ${ }^{[1,2,3-6]}$ hydroxy, ${ }^{[4,7]}$ carbonyl, ${ }^{[3,7-9]}$ epoxy, $[1,3,5,7,10]$ amino, $[1,3,6,11]$ and sulfide $[5,12]$ substituents. Hydrosilylation reactions of unsaturated organic compounds such as olefins and ketones (aldehydes) are commonly and widely used in the industry. However, the chemoselective hydrosilylation of olefins and ketones is challenging. For compounds containing both olefin and ketone moieties, several reactions have demonstrated olefin ${ }^{[1,7-9]}$ and ketone selectivity ${ }^{[13]}$ To exhibit selectivity, each catalyst has its own distinctive ligand; however, catalysts with selectivity for olefin/ketone hydrosilylation that can be converted by simply changing the reaction conditions have not been reported to date.

Recently, iron complexes with an iminobipyridine derivative ligand (Figure 1) have been reported to exhibit high catalytic activity for hydrosilylation of olefin ${ }^{[14]}$ and ketone ${ }^{[15]}$ with a much higher catalytic activity for ketone than that for olefin. ${ }^{[15]}$ In addition, the addition of pyridine to the iron-catalyzed system accelerated ketone hydrosilylation, whereas it suppressed the olefin hydrosilylation. ${ }^{[15]}$ These results suggest that a transition metal complex with higher catalytic activity for olefins than that for ketones could be developed. Moreover, the catalytic activity

${ }^{\star}{ }^{*} \quad$ Dr. K. Kobayashi, D. Taguchi, Prof. Dr. T. Moriuchi, Prof. Dr. H. Nakazawa

Department of Chemistry, Graduate School of Science

Osaka City University

Sumiyoshi-ku, Osaka 558-8585

E-mail: nakazawa@sci.osaka-cu.ac.jp

Supporting information for this article is given via a link at the end of the document. for ketones could be enhanced and that for olefins suppressed by the addition of a pyridine, similar to the iron system. Moreover, the chemoselectivity of olefin/ketone hydrosilylation could be switched by the simple addition of pyridine using the same catalyst.

This paper reports (i) the preparation of novel Co complexes bearing an iminobipyridine ligand (Figure 1), (ii) their catalytic activity and chemoselectivity for hydrosilylation of olefins and ketones, and (iii) the effect of pyridine addition on hydrosilylation selectivity.

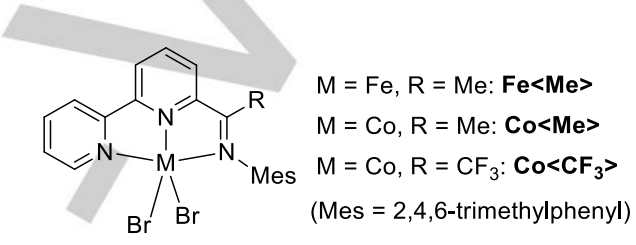

Figure 1. General structure of iminobipyridine complexes and abbreviations used herein.

Many $\mathrm{Fe}$ complexes with iminobipyridine derivatives have been prepared. ${ }^{[14,15]}$ Two corresponding Co complexes $(R=M e$ $(\mathbf{C o}<\mathrm{Me}>), \mathrm{CF}_{3}\left(\mathbf{C o}<\mathrm{CF}_{3}>\right)$ were selected herein, which were newly prepared via reactions of the corresponding ligands with $\mathrm{CoBr}_{2}$, and subjected to catalytic hydrosilylation of olefins and ketones.

First, the results of hydrosilylation of olefins will be described. In the hydrosilylation of 1-octene with $\mathrm{Ph}_{2} \mathrm{SiH}_{2}, \mathrm{Co}<\mathrm{Me}>$ showed high catalytic activity, similar to that of $\mathrm{Fe}<\mathrm{Me}>$, but with different regioselectivity. For Co<Me>, two isomers, the antiMarkovnikov-type compound (1a) and Markovnikov-type compound (1b) were afforded in $52 \%$ and $21 \%$ yields, respectively (Eq. (1)). In contrast, when $\mathrm{Fe}<\mathrm{Me}>$ was used as a catalyst, only the anti-Markovnikov-type compound (1a) was obtained. ${ }^{[14]}$

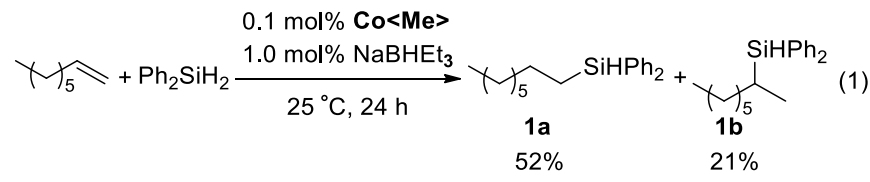

Next, the catalytic activity of $\mathbf{C o}<\mathbf{M e}>$ for styrene $(\mathbf{2 a})$ and $\alpha$ methylstyrene $(\mathbf{2} \mathbf{b})$ was examined under the reaction conditions shown in Table 21. The reaction using $\mathrm{Co}<\mathrm{Me}>$ at $25^{\circ} \mathrm{C}$ mainly afforded the anti-Marcovnikov-type product (3a), however it contained small amount of unknown by-product (Entry 1). In contrast, at $0{ }^{\circ} \mathrm{C}, \mathrm{Co}<\mathrm{Me}>$ showed regioselective hydrosilylation activity for $\mathbf{2 a}$, affording only the anti-Marcovnikov-type product (3a) in $91 \%$ yield (Entry 2). The catalytic activity was the same as that of $\mathbf{F e}<\mathrm{Me}>$ (producing only $\mathbf{3 a}$ in $85 \%$ yield; Entry 3 ). In contrast, $\mathbf{C o}<\mathbf{M e}>$ did not convert $\mathbf{2 b}$ into $\mathbf{3 b}$ at all (Entry 4 ) likely 
due to the steric hindrance of the methyl group blocking the approach of the $\mathrm{C}=\mathrm{C} \pi$-bond to the catalytically active center.

Because pyridine addition suppressed the catalytic activity of olefin hydrosilylation by $\mathrm{Fe}<\mathrm{Me}>,{ }^{[15]}$ the $\mathrm{Co}<\mathrm{Me}>$ system was examined for similar effects. In the presence of pyridine, yields of catalytic hydrosilylation by $\mathrm{Co}<\mathrm{Me}>$ decreased to $29 \%$ at $25^{\circ} \mathrm{C}$ (Table 1, Entry 5) and $11 \%$ at $0{ }^{\circ} \mathrm{C}$ (Entry 6). The suppression effect by pyridine addition was larger at lower temperature. But the pyridine effect on $\mathrm{Co}<\mathrm{Me}>$ catalysis was not as sensitive as $\mathrm{Fe}<\mathrm{Me}>.^{[15]}$ For the suppression of olefin hydrosilylation by $\mathrm{Co}<\mathrm{Me}>$, a large amount of pyridine was required; in Table 1, the same volume of pyridine with $\mathrm{Ph}_{2} \mathrm{SiH}_{2}$ was added (Entries 5 and 6). This may originate from the difference between the association constants of the two complexes and pyridine.

Table 1. Hydrosilylation of styrene derivatives with $\mathrm{Ph}_{2} \mathrm{SiH}_{2}$ catalyzed by $\mathrm{Fe}$ -

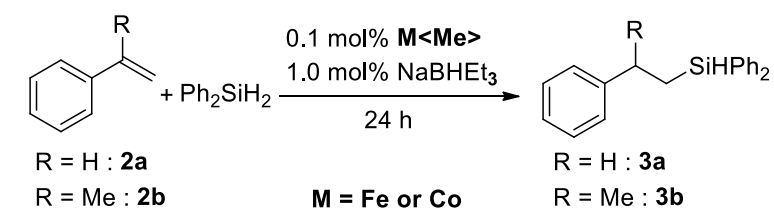

and Co-iminobipyridine complexes.

\begin{tabular}{cccccc}
\hline Entry & Cat. & Solvent & $\begin{array}{c}\text { Temp. } \\
\left({ }^{\circ} \mathrm{C}\right)\end{array}$ & Substrate & $\begin{array}{c}\text { Yield } \\
(\%)^{[a]}\end{array}$ \\
\hline 1 & Co<Me $>$ & Neat & $\mathbf{2 5}$ & $\mathbf{2 a}$ & 81 \\
2 & Co $<$ Me $>$ & Neat & $\mathbf{0}$ & $\mathbf{2 a}$ & 91 \\
3 & Fe<Me $>$ & Neat & $\mathbf{0}$ & $\mathbf{2 a}$ & 85 \\
4 & Co $<$ Me $>$ & Neat & $\mathbf{0}$ & $\mathbf{2 b}$ & N.D. \\
5 & Co $<$ Me $>$ & Pyridine ${ }^{[\mathrm{b}]}$ & $\mathbf{2 5}$ & $\mathbf{2 a}$ & 29 \\
6 & Co $<$ Me $>$ & Pyridine $^{[\mathrm{b}]}$ & $\mathbf{0}$ & $\mathbf{2 a}$ & 11 \\
\hline
\end{tabular}

[a] Based on $\mathrm{Ph}_{2} \mathrm{SiH}_{2}$. [b] $\mathrm{Ph}_{2} \mathrm{SiH}_{2}$ :pyridine = 1:1 (v/v).

As mentioned above, the Co complex bearing an iminobipyridine derivative $(\mathrm{Co}<\mathrm{Me}>)$ exhibited high catalytic activity for olefin hydrosilylation and a suppression effect of pyridine addition on hydrosilylation was observed. Next, the hydrosilylation reactions of ketone using the Co complex as a catalyst was examined and the results of hydrosilylation of acetophenone with $\mathrm{Ph}_{2} \mathrm{SiH}_{2}$ are shown in Table 2 .

$\mathbf{C o}<\mathrm{Me}>$ promoted hydrosilylation of $\mathbf{4}$ to afford $\mathbf{4 a}$ in a good yield (Entry 2). However, the reaction rate was much slower than that of $\mathbf{F e}<\mathbf{M e}>$. To complete the catalytic reaction, $\mathbf{F e}<\mathbf{M e}>$ required $1 \mathrm{~h}$, whereas $\mathrm{Co}<\mathrm{Me}>$ performed the reaction in $24 \mathrm{~h}$ (Entries 1 and 2). The catalytic rate of $\mathrm{Fe}<\mathrm{Me}>$ was unchanged even at $0{ }^{\circ} \mathrm{C}$ (Entry 3), whereas that of $\mathrm{Co}<\mathrm{Me}>$ decreased to almost one-third of the original rate at $0{ }^{\circ} \mathrm{C}$ (Entry 4). The hydrosilylation of acetophenone catalyzed by $\mathrm{Co}<\mathrm{Me}>$ was significantly affected by temperature.
Considering the acceleration effect of pyridine on ketone hydrosilylation reported for the $\mathrm{Fe}<\mathrm{Me}>$ catalytic system, ${ }^{[15]}$ the hydrosilylation of acetophenone catalyzed by $\mathrm{Co}<\mathrm{Me}>$ was performed in pyridine. The poor reactivity of $\mathrm{Co}<\mathrm{Me}>$ toward ketone hydrosilylation at low temperature was remarkably improved in pyridine from $32 \%$ to $79 \%$ (Entry 5). These results strongly suggest that $\mathbf{C o}<$ Me $>$ effectively catalyzes olefin hydrosilylation in the absence of pyridine and ketone

Table 2. Hydrosilylation of acetophenone with $\mathrm{Ph}_{2} \mathrm{SiH}_{2}$ catalyzed by $\mathrm{Fe}$ or Co

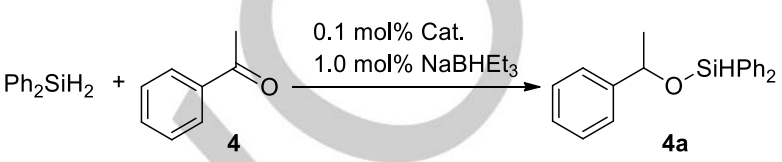

iminobipyridine complexes.

\begin{tabular}{cccccc}
\hline Entry & Cat. & Solvent & $\begin{array}{c}\text { Temp. } \\
\left({ }^{\circ} \mathrm{C}\right)\end{array}$ & Time $(\mathrm{h})$ & $\begin{array}{c}\text { Yield } \\
(\%)^{[\mathrm{a}]}\end{array}$ \\
\hline 1 & Fe<Me> & Neat & 25 & 1 & 91 \\
2 & Co<Me> & Neat & 25 & 24 & 87 \\
3 & Fe<Me> & Neat & 0 & 1 & 88 \\
4 & Co<Me> & Neat & 0 & 24 & 32 \\
5 & Co<Me> & Pyridine & & 24 & 79 \\
\hline
\end{tabular}

[a] Based on $\mathrm{Ph}_{2} \mathrm{SiH}_{2}$. [b] $\mathrm{Ph}_{2} \mathrm{SiH}_{2}$ :pyridine = 1:1 (v/v).

hydrosilylation in its presence.

Olefin/ketone chemoselectivity was also examined for Co<Me $>$ and $\mathbf{F e}<M e>$. To a 1:1 mixture of styrene (2a) and acetophenone (4), $0.1 \mathrm{~mol} \% \mathrm{Co}<\mathrm{Me}>$ or $\mathbf{F e}<\mathrm{Me}>$ and $1.0 \mathrm{~mol} \%$ $\mathrm{NaBHEt}_{3}$ were added, the mixture was stirred at $0{ }^{\circ} \mathrm{C}$ for $24 \mathrm{~h}$ and the products were examined (Table 3 ).

The hydrosilylation catalyzed by $\mathrm{Fe}<\mathrm{Me}>$ afforded only the ketone hydrosilylated compound (4a) (Entry 1). In contrast, the Co<Me> system mainly produced the olefin hydrosilylation compound (3a) with a small amount of $\mathbf{4 a}$ (Entry 2). Therefore, the chemoselectivity of olefin/ketone hydrosilylation was controlled by selection of a metal center bearing an iminobipyridine ligand. $\mathbf{C o}<\mathbf{C F}_{3}>$ afforded $\mathbf{3 a}$ as a main product, but the yield of the by-product (4a) increased compared to Co<Me $>$ (Entry 3). The introduction of an electron-withdrawing group at the imino carbon of the iminobipyridine ligand induced ketone hydrosilylation and an electron-donating group promoted olefin hydrosilylation. It has been reported that the electron density of the central metal affects the affinity for various substrates; an electron-deficient metal center favors ketone coordination and an electron-rich center prefers olefin coordination. ${ }^{[8]}$

Table 3, Entry 4 showed quite interesting results, as pyridine addition to the $\mathrm{Co}<\mathrm{Me}>$ reaction system changed the product completely from $\mathbf{3 a}$ to $\mathbf{4 a}$. This indicates that the chemoselectivity of olefin/ketone hydrosilylation can be switched 
by simple pyridine addition to the reaction system, despite using the same Co<Me $>$ catalyst.

Table 3. Chemoselective hydrosilylation of a 1:1 mixture of styrene and acetophenone with $\mathrm{Ph}_{2} \mathrm{SiH}_{2}$ catalyzed by $\mathrm{Fe}$ - and Co-iminobipyridine

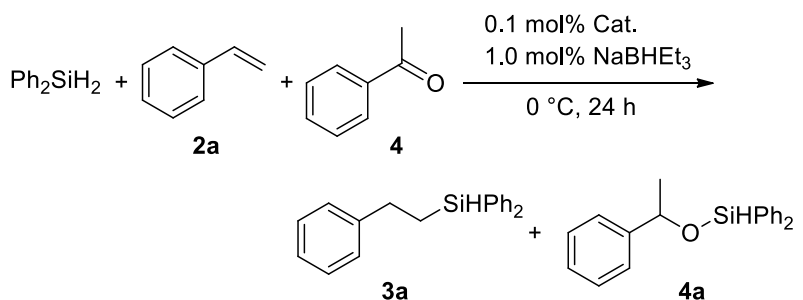

complexes.

\begin{tabular}{|c|c|c|c|c|}
\hline \multirow{2}{*}{ Entry } & \multirow{2}{*}{ Cat. } & \multirow{2}{*}{ Solvent } & \multicolumn{2}{|c|}{ Yield $(\%)^{[\mathrm{a}] \mathrm{b}]}$} \\
\hline & & & $3 a$ & $4 a$ \\
\hline 1 & $\mathrm{Fe}<\mathrm{Me}>$ & Neat & N.D. & 73 \\
\hline 2 & Co $<M e>$ & Neat & 92 & 5 \\
\hline 3 & $\mathrm{Co}<\mathrm{CF}_{3}>$ & Neat & 69 & 19 \\
\hline 4 & Co $<M e>$ & Pyridine ${ }^{[c]}$ & N.D. & 71 \\
\hline
\end{tabular}

[a] Based on $\mathrm{Ph}_{2} \mathrm{SiH}_{2}$. [b] Determined by GC. [c] $\mathrm{Ph}_{2} \mathrm{SiH}_{2}$ :pyridine = 1: $(\mathrm{v} / \mathrm{v})$.

Finally, 3-acetylstyrene (5) was used as a substrate for the Co<Me> catalyzed hydrosilylation because $\mathbf{5}$ contains both ketone and olefin moieties. The results are shown in Table 4. In the absence of pyridine, the olefin hydrosilylation product (5a) was obtained (Entry 1). In contrast, in the presence of pyridine, only the ketone hydrosilylation product $(\mathbf{5 b})$ was afforded (Entry 2). The chemoselectivity was perfect because the other hydrosilylation product was not formed at all. Effect of other solvents on olefin/ketone hydrosilylation was also investigated. Upon adding THF and toluene, Co<Mes showed olefinselectivity in hydrosilylation of 3-acetylstyrene, of which yields were moderately lower than that in neat conditions (Entries 3 and 4). Addition of triethylamine switched chemoselectivity from olefin to ketone, which was similar to pyridine (Entries 5 and 6). But the reaction rate of ketone hydrosilylation was lower than that in the presence of pyridine. It has been reported that additional triethylamine also accelerates ketone hydrosilylation catalyzed by Fe-iminobipyridine complex and acceleration effect of triethylamine is lower than that of pyridine. ${ }^{[15]}$ Effect of triethylamine on $\mathrm{Co}<\mathrm{Me}>$ catalysis is consistent with that of $\mathrm{Fe}$ iminobipyridine complex. The less acceleration effect of triethylamine probably comes from less coordination ability of it than that of pyridine.

The mechanism of pyridine-induced switching of the chemoselectivity was also examined. The role of pyridine was tentatively proposed based on a Chalk-Harrod-type mechanism.
Table 4. Chemoselective hydrosilylation of 3-acetylstyrene with $\mathrm{Ph}_{2} \mathrm{SiH}_{2}$<smiles>C=Cc1cccc(C(C)=O)c1</smiles>

5

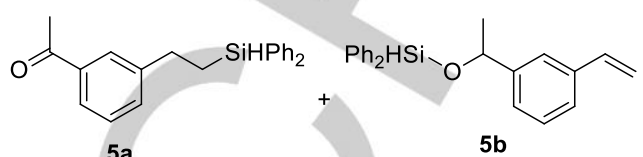

$5 a$

$0.10 \mathrm{~mol} \% \mathrm{Co}<\mathrm{Me}>$

$1.0 \mathrm{~mol}^{2} \mathrm{NaBHEt}_{3}$

catalyzed by a Co-iminobipyridine complex.

\begin{tabular}{|c|c|c|c|c|}
\hline \multirow{2}{*}{ Entry } & \multirow{2}{*}{ Solvent } & \multirow{2}{*}{ Time (h) } & \multicolumn{2}{|c|}{ Yield (\%) ${ }^{[\mathrm{a}]}$} \\
\hline & & & $5 a$ & $5 b$ \\
\hline 1 & Neat & 24 & 93 & N.D. \\
\hline 2 & Pyridine ${ }^{[b]}$ & 3 & N.D. & 90 \\
\hline 3 & $\mathrm{THF}^{[\mathrm{b}]}$ & 24 & 80 & N.D. \\
\hline 4 & Toluene $^{[\mathrm{b}]}$ & 24 & 72 & N.D. \\
\hline 5 & Triethylamine ${ }^{[b]}$ & 3 & N.D. & 44 \\
\hline 6 & Triethylamine $^{[b]}$ & 24 & N.D. & 83 \\
\hline
\end{tabular}

[a] Based on $\mathrm{Ph}_{2} \mathrm{SiH}_{2}$. [b] $\mathrm{Ph}_{2} \mathrm{SiH}_{2}$ :solvent $=1: 1(\mathrm{v} / \mathrm{v})$.
Scheme 1 shows a plausible catalytic cycle in the absence of pyridine where the active $\mathrm{Co}^{\circ}$ species $(\mathbf{A})$ is first generated from the Co dibromo complex depicted as [Co]- $\mathrm{Br}_{2}$ and $\mathrm{NaBHEt}_{3}$. As A is a 15 e species, it readily reacts with $\mathrm{Ph}_{2} \mathrm{SiH}_{2}$ to form the Cosilyl hydrido complex (B). It was experimentally determined that acetophenone $(\mathrm{PhMeC}=\mathrm{O})$ reacts via hydrosilylation, whereas $\alpha$ methylstyrene $\left(\mathrm{PhMeC}=\mathrm{CH}_{2}\right)$ is not inactive, suggesting that the coordination mode of ketone to $\mathbf{B}$ is $\eta^{1}$-type $(\mathbf{E})$ whereas that of olefin is $\eta^{2}$-type $(\mathbf{C})$. After formation of $\mathbf{E}, \mathbf{C}=\mathrm{O}$ double bond insertion into the $\mathrm{Co}-\mathrm{H}$ bond occurs to yield $\mathbf{F}$, followed by the reductive elimination of the silyl and alkoxy groups to produce the ketone hydrosilylation product and $\mathbf{A}$. When the olefin coordinates to $\mathbf{B}$ to form $\mathbf{C}, \mathbf{C}=\mathbf{C}$ double bond insertion into the $\mathrm{Co}-\mathrm{H}$ bond occurs to afford $\mathbf{D}$ followed by the reductive elimination of the silyl and the alkyl groups from $\mathbf{D}$ to yield the olefin hydrosilylation product and $\mathbf{A}$. The experimental results for the Co catalyzed system suggest that ketone hydrosilylation is more significantly affected by reaction temperature than olefin hydrosilylation. This indicates that there is energy barrier to overcome in the ketone hydrosilylation cycle (left cycle in Scheme 1). In the previous report about the catalysis of Feiminobipyridine complexes, the rate limiting step of ketone hydrosilylation is the reductive elimination of a product, which was suggested by the electronic effect of a substituent of a ketone substrate. ${ }^{[15]}$ In this study, introducing an electronwithdrawing group $\left(\mathrm{CF}_{3}\right)$ at the imino carbon promoted ketone hydrosilylation. In left cycle of Scheme 1, the electron deficiency of a Co cation by a $\mathrm{CF}_{3}$ group only facilitate the reductive 
elimination step from $\mathbf{F}$ to $\mathbf{A}$. These results are consistent with the results of a previous report of Fe-iminobipyridine complexes. ${ }^{[15]}$ Therefore, the Co catalyst system preferentially undergoes olefin-selective hydrosilylation over ketone hydrosilylation involving the rate limiting step.

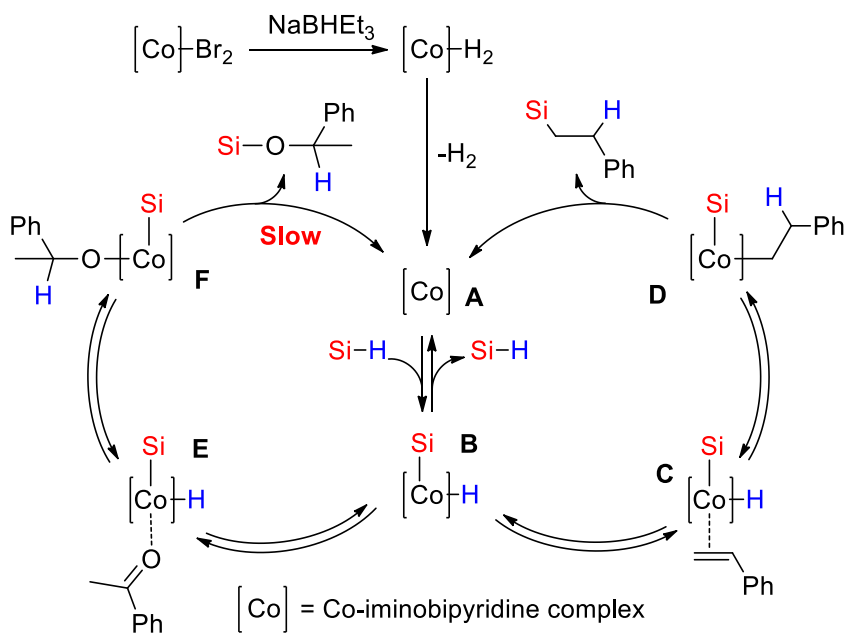

Scheme 1. The possible mechanism of acetophenone/styrene hydrosilylation catalyzed by the Co-iminobipyridine complex. ability of olefin using the $\pi$-electrons from the $\mathrm{C}=\mathrm{C}$ double bond is considerably lower than that of pyridine with its lone pair. Therefore, olefin hydrosilylation is suppressed by upon pyridine addition. In contrast, the coordination ability of the ketone is expected to be higher than that of olefin, as ketone coordinates using the lone pair on the carbonyl oxygen. Ligand exchange of pyridine in B' to the ketone partially proceeds even in pyridine medium (from B' to E in Scheme 2). Moreover, it was reported that pyridine coordination decreases the energy barrier for the reductive elimination of silyl and alkoxy groups in F' to form alkoxysilane. ${ }^{15]}$ This effect also drives the selective ketone hydrosilylation.

In conclusion, transition metal complex catalysts were shown to be effective for the hydrosilylation of olefins and ketones. The selectivity for hydrosilylation reactions, which are industrially important reactions, was also investigated. The Co complex bearing an iminobipyridine derivative ligand exhibited high catalytic rates and olefin-selective activity. Considering that the corresponding $\mathrm{Fe}$ complex showed ketone-selective catalytic activity, the selectivity of olefin/ketone hydrosilylation could be changed by altering the central metal with the same ligand. Furthermore, pyridine addition to the catalytic system using this Co complex changed the selectivity to the ketone-selective hydrosilylation reaction. In other words, for the first time a catalytic system was prepared wherein the selectivity of the hydrosilylation of olefin/ketone can be reversed by changing a

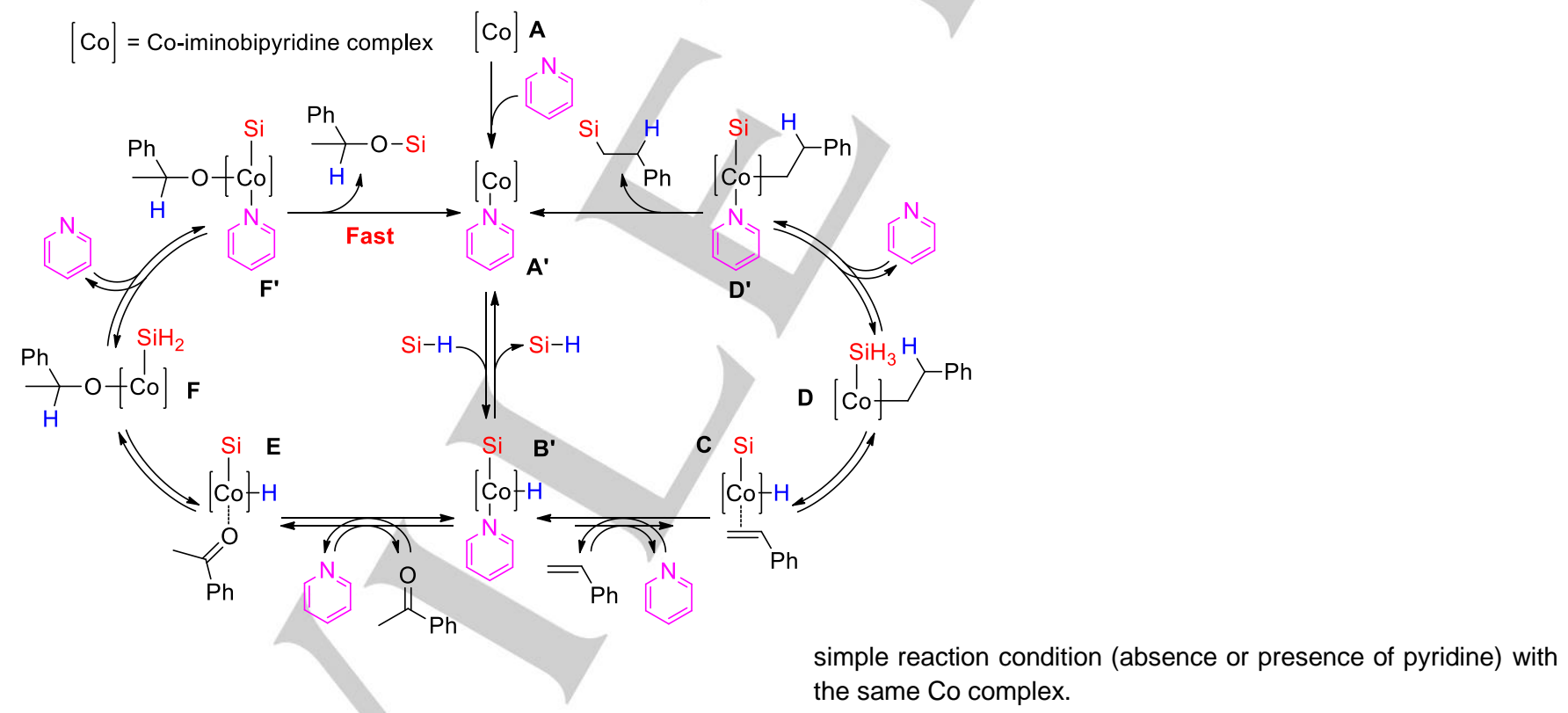

Scheme 2. Possible mechanism of acetophenone/styrene hydrosilylation catalyzed by Co-iminobipyridine complex in the presence of pyridine.

When pyridine is present (Scheme 2), it may coordinate to the $\mathrm{Co}^{0}$ species $(\mathbf{A})$ to form a $\mathrm{Co}^{0}$-pyridine complex $\mathbf{A}^{\prime}$. Oxidative addition of the hydrosilane Si-H bond to A' produces B'. Since B' is a 19 e species, dissociation of pyridine from $\mathbf{B}^{\prime}$ is required prior to coordination of the olefin or ketone. However, the coordination

\section{Acknowledgements}


This work was supported by the "Development of Innovative Catalytic Processes for Organosilicon Functional Materials" project (PL: K. Sato) from the New Energy and Industrial Technology Development Organization (NEDO).

Keywords: Chemoselective hydrosilylation $\cdot$ Co complex $\cdot \mathrm{Fe}$ complex $\cdot$ Hydrosilylation catalyst $\cdot$ Switchable chemoselectivity

[1] I. Buslov, J. Because, S. Mazza, M. Montandon-Clerc, X. Hu, Angew. Chem. Int. Ed. 2015, 54, 14523-14526.

[2] a) C. Chen, M. B. Hecht, A. Kavara, W. W. Brennessel, B. Q. Mercado, D. J. Weix, P. L. Holland, J. Am. Chem. Soc. 2015, 137, 13244-13247 b) X. Du, Y. Zhang, D. Peng, Z. Huang, Angew. Chem. Int. Ed. 2016 $55,6671-6675$

[3] C. H. Schuster, T. Diao, I. Pappas, P. J. Chirik, ACS Catal. 2016, 6 , 2632-2636.

[4] B. Cheng, P. Lu, H. Zhang, X. Cheng, Z. Lu, J. Am. Chem. Soc. 2017, 139, 9439-9442.

[5] C. Wang, W. J. Teo, S. Ge, ACS Catal. 2017, 7, 855-863.

[6] a) C. L. Rock, R. J. Trovitch, Dalton Trans. 2019, 48, 461-467; b) S. Gutiérrez-Tarriño, P. Concepción, P. Oña-Burgos, Eur. J. Inorg. Chem. 2018, 4867-4874.

[7] A. D. Ibrahim, S. W. Entsminger, L. Zhu, A. R. Fout, ACS Catal. 2016, 6, 3589-3593.

[8] D. Peng, Y. Zhang, X. Du, L. Zhang, X. Leng, M. D. Walter, Z. Huang, J. Am. Chem. Soc. 2013, 135, 19154-19166.
[9] a) M. D. Greenhalgh, D. J. Frank, S. P. Thomas, Adv. Synth. Catal 2014, 356, 584-590; b) A. J. Challinor, M. Calin, G. S. Nichol, N. B. Carter, S. P. Thomas, Adv. Synth. Catal. 2016, 358, 2404-2409.

[10] a) A. M. Tondreau, C. C. H. Atienza, J. M. Darmon, C. Milsmann, H. M. Hoyt, K. J. Weller, S. A. Nye, K. M. Lewis, J. Boyer, J. G. P. Delis, E. Lobkovsky, P. J. Chirik, Organometallics 2012, 31, 4886-4893; b) D Noda, A. Tahara, Y. Sunada, H. Nagashima, J. Am. Chem. Soc. 2016 138, 2480-2483; c) V. Srinivas, Y. Nakajima, W. Ando, K. Sato, S. Shimada, J. Organomet. Chem. 2016, 809, 57-62; d) Y. Liu, L. Deng, J. Am. Chem. Soc. 2017, 139, 1798-1801; e) A. Sanagawa, H. Nagashima, Organometallics 2018, 37, 2859-2871.

[11] C. C. H. Atienza, T. Diao, K. J. Weller, S. A. Nye, K. M. Lewis, J. G. P. Delis, J. L. Boyer, A. K. Roy, P. J. Chirik, J. Am. Chem. Soc. 2014, 136, 12108-12118.

[12] a) S. Ding, L.-J. Song, Y. Wang, X. Zhang, L. W. Chung, Y.-D. Wu, J. Sun, Angew. Chem. Int. Ed. 2015, 54, 5632-5635; b) V. Srinivas, $Y$ Nakajima, K. Sato, S. Shimada, Org. Lett. 2018, 20, 12-15; c) X. Xie, X. Zhang, H. Yang, X. Ji, J. Li, S. Ding, J. Org. Chem. 2019, 84, 10851093.

[13] a) A. M. Tondreau, E. Lobkovsky, P. J. Chirik, Org. Lett. 2008, 10, 2789-2792; b) J. Yang, T. D. Tilley, Angew. Chem. Int. Ed. 2010, 49 10186-10188; c) T. K. Mukhopadhyay, M. Flores, T. L. Groy, R. J. Trovitch, Chem. Sci. 2018, 9, 7673-7680.

[14] a) K. Hayasaka, K. Kamata, H. Nakazawa, Bull. Chem. Soc. Jpn. 2016 89, 394-404; b) Y. Toya, K. Hayasaka, H. Nakazawa, Organometallics 2017, 36, 1727-1735; c) K. Kobayashi, S. Teratani, Y. Izumori, K. Hayasaka, H. Nakazawa, Bull. Chem. Soc. Jpn. 2019, 92, 105-114.

[15] K. Kobayashi, Y. Izumori, D. Taguchi, H. Nakazawa, ChemPlusChem 2019, 84, 1094-1102. 
Entry for the Table of Contents (Please choose one layout)

Layout 2:

\section{COMMUNICATION}

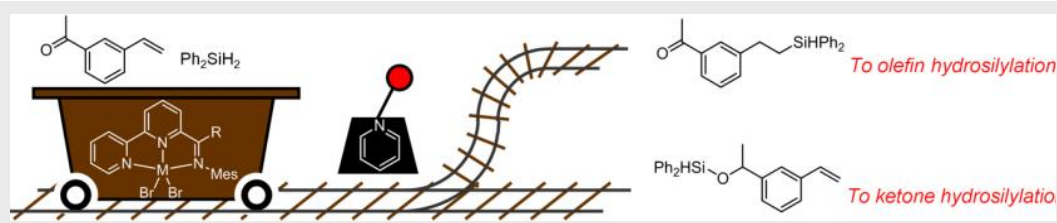

The chemoselective hydrosilylation catalyzed by Fe- and Co-iminobipyridine complexes was invesitigated; the former catalyzed ketone hydrosilylation and the latter facilitated olefin hydrosilylation at $0{ }^{\circ} \mathrm{C}$. Furthermore, the chemoselectivity of Co complex could be changed from olefin to ketone by pyridine addition to the reaction system.
Katsuaki Kobayashi, * Daisuke Taguchi, Toshiyuki Moriuchi, Hiroshi Nakazawa*

Page No. - Page No.

Chemoselectivity conversion of the olefin/ketone hydrosilylation reaction catalyzed by $\mathrm{Fe}$ and Co complexes bearing an iminobipyridine ligand 